\title{
MOUNTAIN ACCIDENTS
}

\author{
I. A. CAMPBELL, Ch.M., F.R.C.S. \\ Belford Hospital, Fort William, Invernessshire
}

\section{Introduction}

Many of the people in this Association are concerned with youth expeditions into the mountains and at the moment, this is perhaps an activity that has had some bad publicity. One never hears of the successful expeditions but if through accident or error of judgement something goes wrong, the news media are on to it quickly and in no time the headlines appear throughout the country. It is therefore very important that all who venture into the mountains whether in summer or in winter are equipped both physically and mentally for the rigours which may be encountered. I live in an area where the facilities for climbing are probably the best in the country and therefore we have to deal with perhaps more mountain accidents than many other hospitals. It is my impression, that with ever increasing car ownership, more and more people are able to come out to the wide open spaces from the urban centres to enjoy these outdoor activities and therefore the population at risk is an ever increasing one. It is not unusual for people to motor all night on Friday from the Midlands or south of England to Glencoe or to Ben Nevis, to climb all day Saturday and Sunday and drive home throughout Sunday night. It is therefore very important that every opportunity be taken to educate the public about the risks involved in expeditions on the mountains and to try to put across a few simple rules of safety. This Association is probably one of the best equipped to do this job.

Mountaineering is probably one of the finest forms of recreation this country has to offer its young people and while it makes great physical and mental demands on the individual, it is also dangerous. The element of danger is probably one of the great attractions and is part of the challenge of mountains to the mountaineer. There has been an increase in accidents however, and many of these need not have happened had there not been complete disregard for the rules of safety. Not all mountain accidents are reported to the Mountain Rescue Committee and therefore the published figures probably only represent a fraction of the accidents that occur, and give no indication of the hours spent in search and rescue operations where the people in difficulty are subsequently found uninjured, or who, having been lost, manage to find their own way home. In all fairness, one must point out that it is not only the mountaineer who gets into difficulty and hill walkers form quite a large percentage of the incidents.

The surgeon's role in mountain accidents is to treat the casualty when he is brought to the hospital and he should not go out on rescues where he would almost certainly get into difficulty and be unable to give any assistance, but one cannot practise surgery at the foot of Ben Nevis for almost thirteen years and divorce oneself from the problem of mountain accidents. Indeed, it is doubtful if a doctor can do much more at the site of an accident than a well-trained mountain rescue man.

The great difference between mountain accidents and accidents on the road, in the home, or in the factory, is that mountain accidents usually occur in awkward places at awkward times and in bad weather conditions. The Glencoe and Ben Nevis areas provide about seventy per cent of the mountain accidents in Scotland and Glencoe is the main accident area. On several occasions, more than one accident has occurred in the same day and this puts a very great strain on the mountain rescue teams. I will make no detailed mention of the fatal accidents which do not concern us in this paper but in the years 1954-68, there were forty-two fatal accidents on Ben Nevis. Compared with the 1925-1945 period, this represents a ten fold increase. Fifty-four per cent of the accidents involved people under twenty and a further thirty per cent between the ages of twenty and twenty-five. Therefore over eighty per cent of persons involved in mountain accidents were under the age of twenty-five. The increase in accidents may be explained by the greater number of people who can now avail themselves of the opportunities for walking and climbing in the hills of Scotland but there is some evidence to suggest that in the pre-War period, a longer period of apprenticeship was required before one ventured on the really severe climbs. In this paper, I propose to describe briefly the clinical features of exposure and to emphasise some of the precautions which should be taken to avoid it particularly when dealing with injured persons and then to give an indication of the number and nature of mountain accidents seen in Fort William over the past thirteen years.

Climbing is probably one of the most energetic of human activities and as a result of severe exertion, climbers may become physically exhausted and unable to carry on without prolonged adequate rest. This state of exhaustion is probably due to a decrease in energy stores and decrease in blood sugar; to dehydration and loss of salt and to loss of heat due to blood being diverted to the exercising tissues where heat is more easily lost.

It takes little imagination to understand what happens on the mountain when the unwary climber becomes exhausted, especially in the conditions which 
sometimes prevail. Winds on the Ben Nevis range reach their maximum velocity in January and in November and vary from eighty to a hundred and fifty miles per hour and their maximum force is reached at night. The daily temperature on Ben Nevis is below freezing for seven months of the year, a factor which tourists do not take into account and the lowest temperature recorded is minus seventeen degrees Fahrenheit. One must always remember that there is a great temperature difference between sea level and 4,000 feet and it is reckoned that there is a fall of 1 degree Fahrenheit for every three hundred feet of altitude. Thus if the temperature is freezing at sea level, there may be anything from 15 to 28 degrees of frost on the summit of a mountain in the three to four thousand foot range. If conditions in addition are damp and properly insulated clothing is not being worn, the dangers of exposure are much greater than in dry cold.

The clinical features of exhaustion have been described in detail by Pugh (1966). The man who is exhausted may begin to act unreasonably. He complains of physical and mental lethargy and fails to respond or to understand questions on instructions and there may be abnormalities of vision which is a very ominous sign. There may be slurring of the speech with violent outbursts of energy and almost drunken behaviour and the victim may start falling and stumbling and this may well explain why so many accidents occur after a hard day's climbing and not at the beginning. Collapse may occur as soon as two hours after the onset of symptoms and death may occur within two hours of collapse. It is therefore particularly important for persons who are in charge of parties on the hill to be able to recognise the signs of impending exhaustion and to treat the victim so that his condition does not deteriorate into the full-blown exposure syndrome. When the normal individual is subjected to cold, he maintains his body temperature by constricting his peripheral vessels and mobilising his reserves. He starts to shiver in order to produce the required heat to keep his body temperature within normal limits. The exhausted cold victim however, can no longer raise his body temperature by shivering and his body "core" temperature continues to fall. It is therefore of the utmost importance to recognise the signs of exhaustion early and all possible heat must be conserved and the victim must not be forced to go on walking. He must be rested and he must be rested in shelter and any form of covering must be used in order to try and conserve as much heat as possible. No attempt must be made to try and warm up the extremities as this will cause further heat loss and lower the body "core" temperature still further. Glucose in the form of tablets or of chocolate should always be carried and should be given to the victim of exhaustion to help replace his depleted energy reserves. Unfortunately, many of the injured victims are unconscious and are unable to swallow. On no account must the victim of exhaustion be allowed to walk off the hill even after the rescue party arrives. He must be carried. If the victim has been injured the dangers of exposure are greater because he may be completely immobilised as well as suffering from surgical shock. It is therefore even more important that he is kept as warm as possible and any injured limb should be splinted. As far as splinting of injured limbs is concerned, ordinary light malleable wire splints are probably as effective as any. Inflatable splints have the great disadvantage that they become very hard at low temperatures and are difficult to manage. The Laerdal vacuum mattress is at present on trial with our local mountain rescue team.

The first aid management of patients unconscious from mountain accidents does not differ from the management of similar patients as a result of any other accident. Of utmost importance is the maintenance of the airway. It is therefore very important that mountain rescue teams be taught how to maintain a clear airway and unconscious patients should be carried in the head-down position in order to minimise the dangers of inhalation of vomitus, blood, etc. Small portable suction machines working on the aerosol principle are now available and should prove of value to mountain rescue teams.

Many of the minor injuries sustained on the mountains are dealt with by the general practitioners particularly in the Glencoe area, but an increasing number of victims present themselves at the hospital casualty department. There has been a steady increase over the past thirteen years in the numbers of out-patients who have been injured in accidents on the mountains. The more serious cases come direct to the hospital and these may occur either in the Glencoe area, in the Ardnamurchan area, or more usually on the Ben Nevis range. As one would expect, limb and head injuries are the most common and in association, there are very often fractures of ribs with damage to the underlying pleural space or lung. Severe injuries to the chest are uncommon in the cases which survive serious falls. Of the mountain accident admissions over the past thirteen years, some of these victims were skiing but the vast majority were either climbing or hill-walking. Accidents on the mountains nearly always occur at the week-end or during holiday periods such as Christmas or New Year or at Easter-time. They almost invariably occur late in the day and the evacuation of such casualties has to take place in darkness. This means that the evacuation is difficult and dangerous and in many cases is carried out by the local volunteer rescue teams or by those of the R.A.F. The Police are responsible for search and rescue operations on the mountains and in the period 1954-70, the total police man-hours spent on search and rescue operations on the mountains of Inverness-shire was in the region of 8,115 hours. (McClure, 1970) Mountain rescue is becoming increasingly expensive as the 
equipment necessary becomes more sophisticated e.g. walkie-talkie radio, helicopters, etc. and this has been recognised to some extent by the Highlands and Islands Development Board who have granted funds to help in the purchase of the more sophisticated equipment.

\section{Conclusions}

(1) Exposure must be avoided. It is much easier to avoid than it is to treat especially under difficult conditions. Those who venture on the hills must be fit and must plan their route carefully. They should know and remain within their physical capabilities and they must get off the mountains if at all possible before darkness. They should pay much more attention to local knowledge and should not embark upon excursions when conditions are unfavourable or without knowing the severity of the route.

(2) Clothing must be adequate for the job and must be both wind and waterproof and those who venture on the mountains must wear proper boots.

(3) If people are going to climb, they must be properly equipped and if they are going to climb in snow, they must have the knowledge and equipment to cope with the difficulties which may be encountered.
(4) Common sense should be the sheet anchor of those who embark on the mountains and a message should be left at base giving information as to the route and the approximate time of return and on no account should plans be changed without informing someone at base.

(5) We must not stifle the spirit of adventure but it is important to maintain a sense of proportion and young people in their early teens do not have the physical resources of the adult. If one is training commandos, one is dealing with mature individuals and they probably have to be pushed near the limit of human endurance. In dealing with the more immature school child, one has to be much more circumspect or disasters will continue to happen with all the attendant publicity and uninformed criticism.

Climbing accidents hit the headlines but they really cause much less work to hospitals in the area than accidents which occur on the roads and which many appear to accept as inevitable. We are concerned however, with the climber or hill-walker who takes unnecessary risks or who is not adequately trained or equipped for his expedition. He is not only a danger to himself and to the other members of his party but he endangers the lives of volunteers who have to go out to rescue him.

\section{REFERENCES}

1. PUGH, L. G. C. E., British Medical Journal 1: 123. 1966.

2. McCLURE, A. L., 1970, Personal Communication.

\section{REVIEW}

\section{INTERNATIONAL CONGRESS OF WINTER SPORTS MEDICINE}

Publishers: Organising Committee, c/o Department of Physiology, Jikei University School of Nishi-Shinbashi, Minato-Ku, Tokyo, JAPAN.

$172 \mathrm{pp}$, illustrations and references

Price:- None given

This is an excellent publication containing numerous papers of interest to clinicians, physiologists and physical $\Xi$ educationists alike. While winter sports may be somewhat esoteric (anyone for ski-jumping?) the principles underlying for example the biomechanics of trauma remain of universal significance.

Since no price is quoted a letter of enquiry to the publishers would be well worth the price of the stamp.

\section{J. G. P. WILLIAMS, F.R.C.S.}

